\title{
NUMERICAL MODELING OF UNSTEADY FLOW AROUND A BOX CULVERT AND ITS VERIFICATION
}

\author{
Alhinai SAIF ${ }^{1}$, Takashi HOSODA ${ }^{2}$ and Hidekazu SHIRAI ${ }^{3}$ \\ ${ }^{1}$ Member of JSCE, PhD Student, Dep. of Urban Management, Graduate School of Engineering, \\ Kyoto University (C1-No.3, Kyoto-Daigaku-Katsura, Nishikyo-ku, Kyoto 615-8540, Japan) \\ ${ }^{2}$ Member of JSCE, Dr. of Eng., Professor, Dep. of Urban Management, Kyoto University \\ (C1-No.3, Kyoto-Daigaku-Katsura, Nishikyo-ku, Kyoto 615-8540, Japan) \\ ${ }^{3}$ Member of JSCE, Master Student, Dep. of Urban Management, Graduate School of Engineering, \\ Kyoto University (C1-No.3, Kyoto-Daigaku-Katsura, Nishikyo-ku, Kyoto 615-8540, Japan)
}

\begin{abstract}
This paper deals with a numerical model to simulate flow through a box culvert, which represents flow during flash floods under highways in Oman. We firstly show the typical flow patterns with the transition from free surface flows to pressurized flows and overflows over a culvert, based on hydraulic experiments. Then, a numerical model applicable to the full/partial full pressurized flows is tested to simulate the typical flow patterns under the conditions of experiments.

It is pointed out that although the numerical model used here can simulate the simple flow patterns to some extents, the model should be improved further to get better results.
\end{abstract}

Key Words : Open channel flow, pressurized flow, flash flood, culvert

\section{INTRODUCTION}

Flash floods are usually caused by heavy or excessive rainfall in a short period of time. They are one of the most dangerous weather-related natural disasters in the world, and can create hazardous situations for people and cause extensive damages to property.

Oman is one of the arid countries subjected to flash floods. Records show that major flash floods occurred in Oman in 1989, 1997, 2002, 2003, 2005, 2007 and 2010. The literature has shown that flash floods affecting wadis in arid regions like Oman is poorly understood and the modeling are inadequate for prediction, mitigation or management. Therefore numerical models are useful tools to improve flash floods prediction by providing better understanding of the hydrological processes governing flash floods in arid regions.

Due to its proximity to the commercial and business district of Muscat City, the Capital of Oman, wadies intersect with a number of streets, where culverts and bridges have been constructed to provide road flood protection. Culverts were very common used to allow water to pass under highways as shown in Fig. 1. They had also been used to carry watercourses under built-up areas. In many cases the city is flooded because the culverts capacity was insufficient to carry large flood flows. Fig. 2 shows water flow through box culverts during flood seasons.

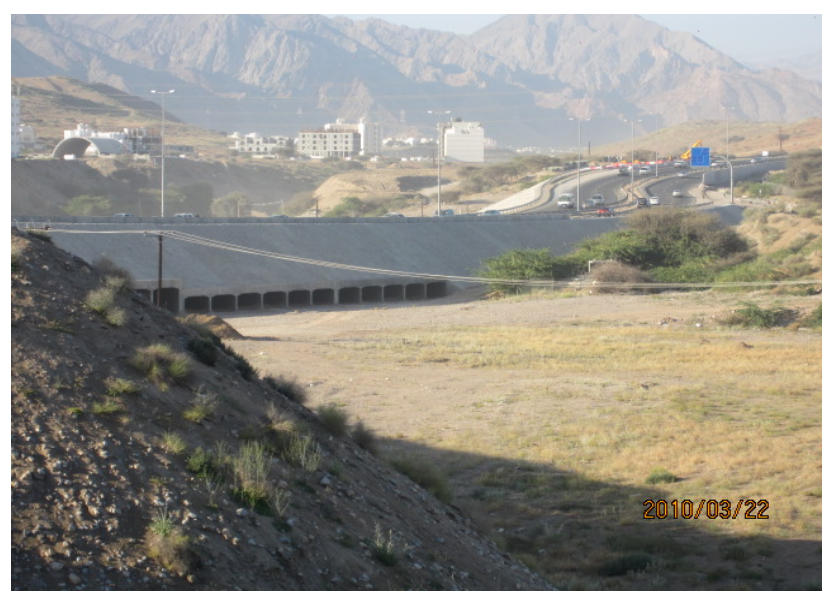

Fig.1 A box culverts constructed under a highway in Muscat. 


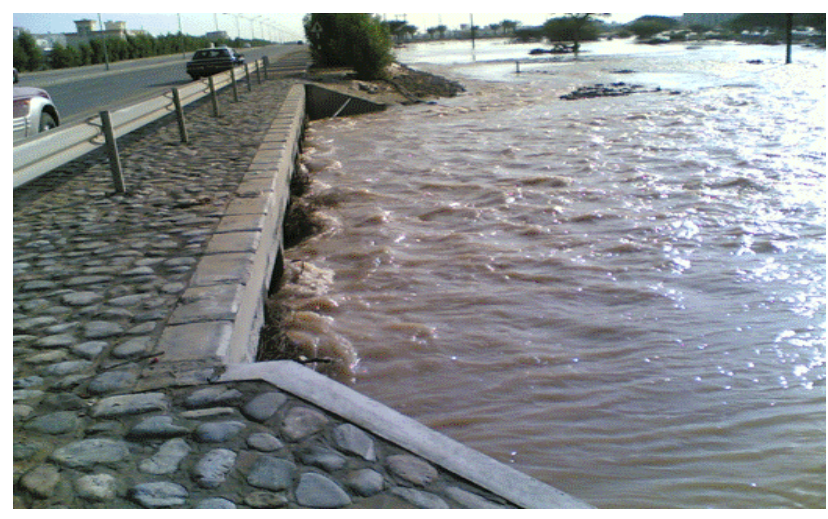

Fig.2 Flow through culverts during flood seasons.

In this paper, we analyzed the typical features of flow through and over culverts by fundamental hydraulic experiments and a numerical model, considering the interaction between free surface flow and pressurized flow. The numerical model is verified by carrying out hydraulic experiments.

It was shown that the hydraulic transients of the interaction between open channel flow and pressurized pipe flow inside the culvert could be produced by using a numerical model.

\section{HYDRAULIC EXPERIMENTS}

The hydraulic experiments were conducted using a horizontal rectangular flume $140 \mathrm{~cm}$ long, $50 \mathrm{~cm}$ wide and $30 \mathrm{~cm}$ high as shown in Fig. 3. The flume is equipped with a tail gate to control the outlet water depth. In order to generate submerged flow over the culvert, the width of the flume is reduced in Run 3 and Run 4 to be equal to the width of the culvert.

Constant discharge is supplied at the upstream end (inlet) into the dry bet flume. After some time, the unsteady flow reaches the steady state. The hydraulic variables in the steady state are listed in

\section{Table 1}

Fig. 4 shows the typical flow patterns appeared in the steady state adjusting the height of tail gate. These flow patterns are summarized as follows:

(a) Run 1: Partly full pipe flow (submerged outlet only, without overflow)

(b) Run 2: Classic full pipe flow (submerged inlet and outlet, without overflow)

(c) Run 3: Free surface open channel flow (submerged inlet only, with overflow)

(d) Run 4: Partly full pipe flow (submerged inlet and outlet, with overflow)

The water surface profiles in the steady state

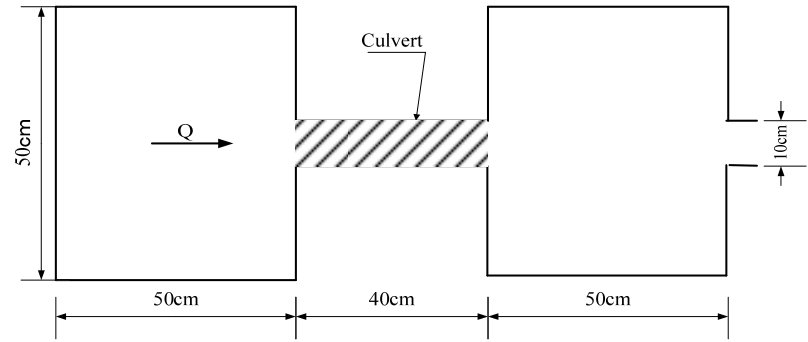

(a) Run 1 \& Run 2

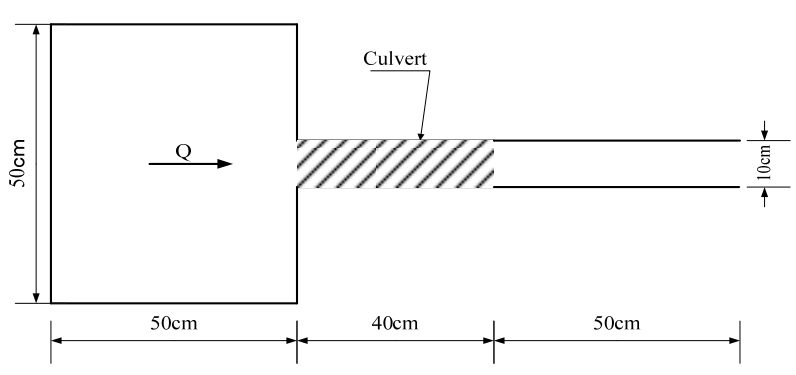

(b) Run 3 \& Run 4

Fig.3 Schematic illustration of experimental setup.

along the center line are shown in Fig. 5. Different types of flow through culverts are taken places depending on the outlets and inlets conditions.

The outlet is submerged in Run 1 as shown in Fig.4(a) and Fig. 5(a), which generate the transition from free surface flow to pressurized flow in the barrel of the culvert.

A type of outlet control occurred in Run (2) as shown in Fig. 4(b) and Fig. 5(b), in which full pressurized flow occurs through the barrel of the culvert. The full pressurized flow was caused by reducing the height of the tailgate, which let backwater to take place. The flow changed gradually from open channel flow to pressurized pipe flow as shown in Fig. 6.

Table 1 Hydraulic variables of laboratory tests.

\begin{tabular}{|c|c|c|c|c|c|c|c|c|}
\hline Run & $\begin{array}{c}\mathrm{Q}^{3} \\
\left(\mathrm{~cm}^{3} / \mathrm{s}\right)\end{array}$ & $\begin{array}{c}\mathrm{B} \\
(\mathrm{cm})\end{array}$ & $\begin{array}{c}\mathrm{B}_{\mathrm{c}} \\
(\mathrm{cm})\end{array}$ & $\begin{array}{c}\mathrm{L}_{\mathrm{c}} \\
(\mathrm{cm})\end{array}$ & $\begin{array}{c}\mathrm{H}_{\mathrm{c}} \\
(\mathrm{cm})\end{array}$ & $\begin{array}{c}\mathrm{h}_{\mathrm{u} / \mathrm{s}} \\
(\mathrm{cm})\end{array}$ & $\begin{array}{c}\mathrm{h}_{\mathrm{d} / \mathrm{s}} \\
(\mathrm{cm})\end{array}$ & $\mathrm{S}_{0}$ \\
\hline 1 & 465.6 & 50 & 10 & 40 & 3.2 & 2.04 & 3.44 & $1 / 443$ \\
\hline 2 & 465.5 & 50 & 10 & 40 & 3.2 & 5.15 & 6.25 & $1 / 443$ \\
\hline 3 & 1946 & 50 & 10 & 40 & 3.2 & 5.05 & 2.61 & $1 / 26$ \\
\hline 4 & 1232 & 50 & 10 & 40 & 3.2 & 5.82 & 5.91 & $1 / 271$ \\
\hline
\end{tabular}

where $\mathrm{Q}=$ flow rate; $\mathrm{B}=$ width of channel; $\mathrm{B}_{\mathrm{c}}=$ width of culvert; $\mathrm{L}_{\mathrm{c}}=$ length of culvert; $\mathrm{H}_{\mathrm{c}}=$ height of culvert; $\mathrm{h}_{\mathrm{u} / \mathrm{s}}=$ water depth upstream culvert; $h_{d / s}=$ water depth downstream culvert; $\mathrm{S}_{0}=$ slope. 


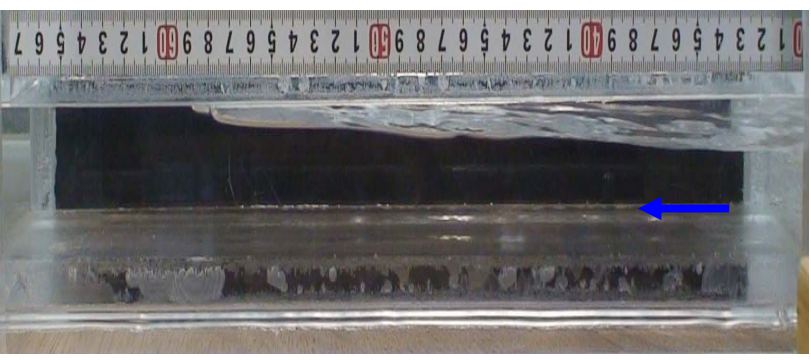

(a)

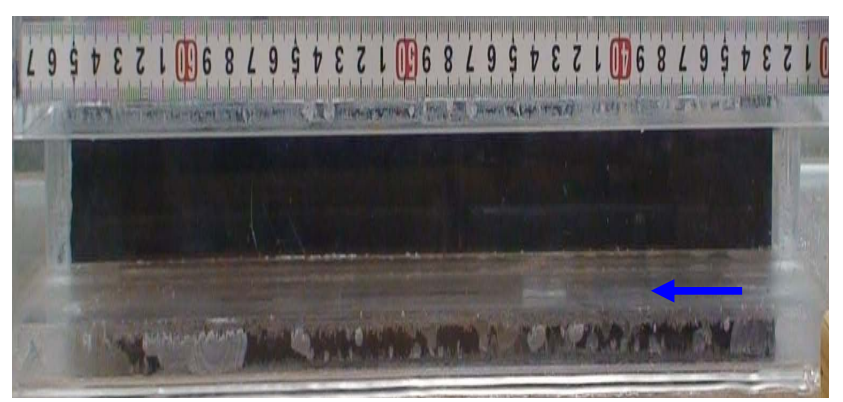

(b)

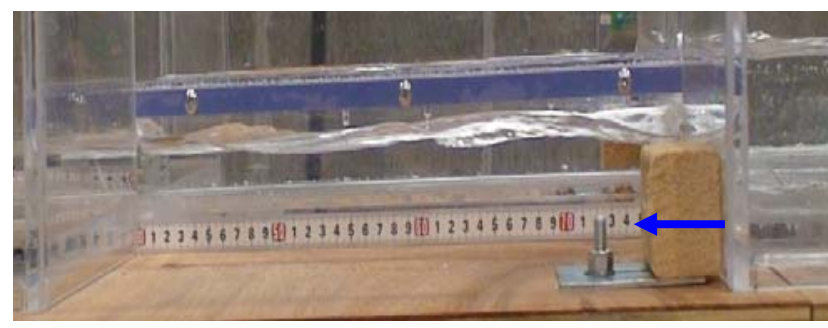

(c)

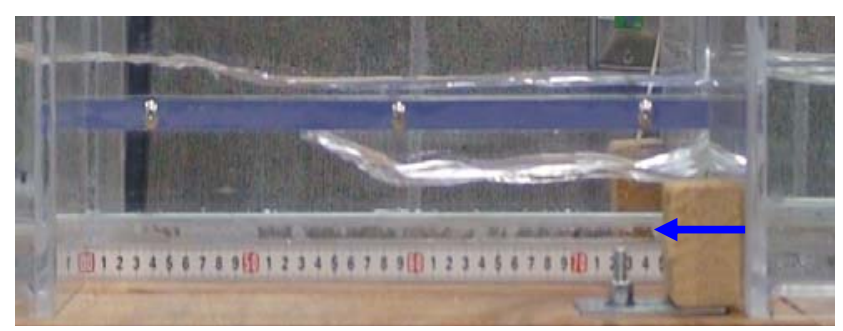

(d)

Fig.4 Flow profiles during experiments for: (a) Run 1, (b) Run 2, (c) Run 3 and (d) Run 4.

Over flow was observed in Run 3 and Run 4 as shown in Fig. 4(c) and Fig. 4(d), respectively. In Run 3 with submerged inlet, the flow with free stream line is observed inside the culvert. In this case, both flows through and over the culvert are free water surface flows. A clear type of outlet control is shown in Fig. 4(d) and Fig. 5(d) where both inlet and outlet are submerged. It occurred by increasing the outlet depth. The transition from free surface flow and pressurized flow occurs through hydraulic jump in the culvert.

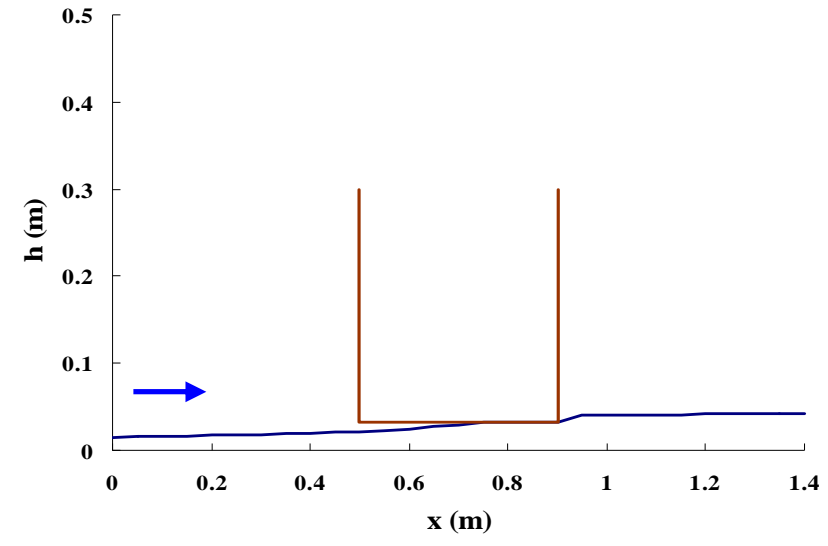

(a)

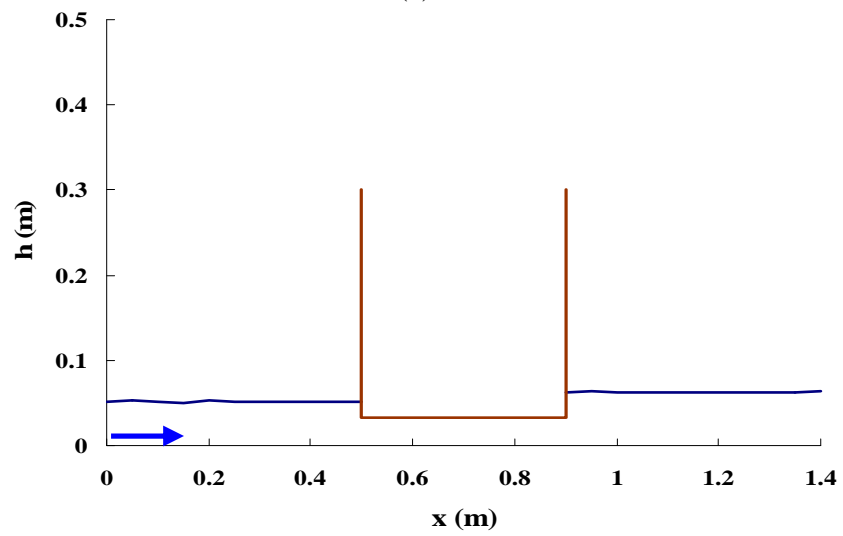

(b)

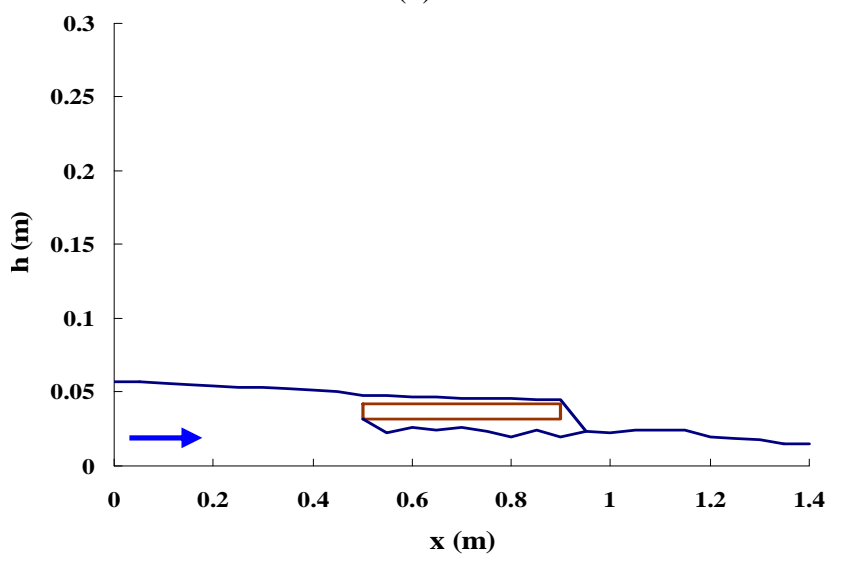

(c)

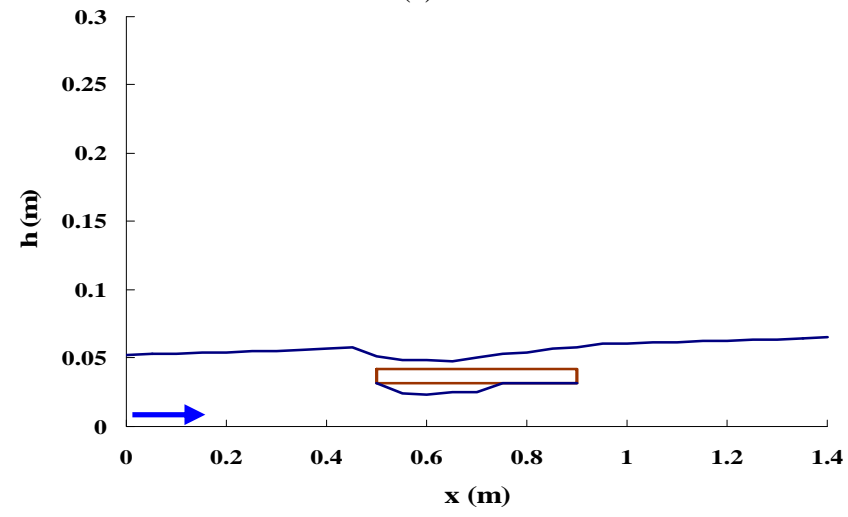

(d)

Fig.5 Surface water variations along centerline for experiments: (a) Run 1, (b) Run 2, (c) Run 3 and (d) Run 4. 


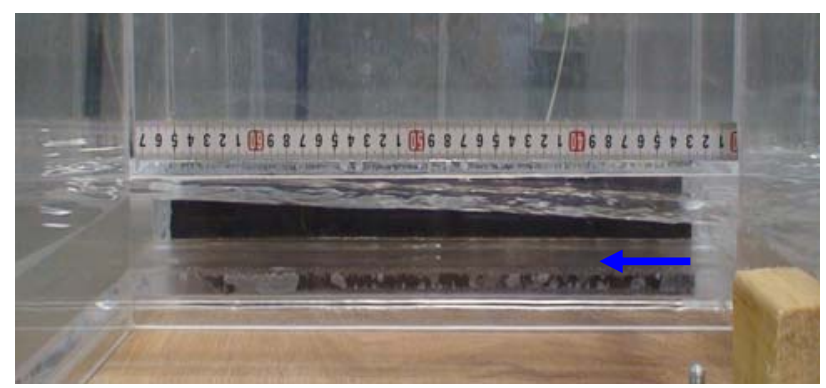

(a) Open channel flow

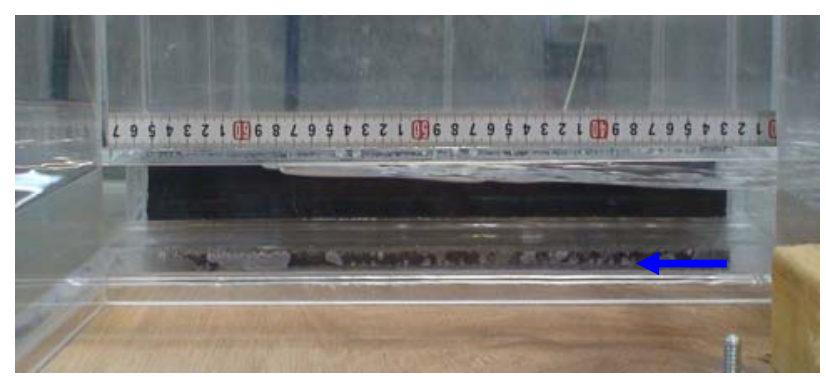

(b) Partial pressurized flow

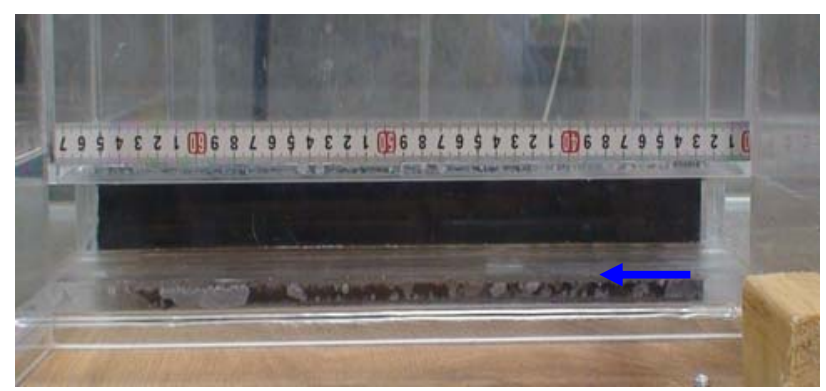

(c) Full pressurized flow

Fig.6 The gradual changes of flow in Run 2.

\section{NUMERICAL METHOD}

The numerical simulations of the hydraulic experiments mentioned above were carried out by using a numerical model developed in literature ${ }^{1,2,3)}$, which can be used to reproduce the transition from free surface flow to pressurized flow in a plane 2-D system.

The numerical model is composed of the continuity and momentum equations of the plane two dimensional flows of open channel flows and pressurized pipe flows and the momentum equation of an interface between both flows. The fundamental equations are given as follow:

[Free surface open channel flow]

$$
\begin{aligned}
& \frac{\partial h}{\partial t}+\frac{\partial M}{\partial x}+\frac{\partial N}{\partial y}=0 \\
& \frac{\partial M}{\partial t}+\frac{\partial U M}{\partial x}+\frac{\partial V M}{\partial y}=-g h \frac{\partial\left(h+z_{b}\right)}{\partial x}-\frac{\tau_{b_{x}}}{\rho} \\
& \frac{\partial N}{\partial t}+\frac{\partial U N}{\partial x}+\frac{\partial V N}{\partial y}=-g h \frac{\partial\left(h+z_{b}\right)}{\partial y}-\frac{\tau_{b_{y}}}{\rho}
\end{aligned}
$$

[Pressurized pipe flow]

$$
\begin{aligned}
& \frac{\partial U D}{\partial x}+\frac{\partial V D}{\partial y}=0 \\
& \frac{\partial U D}{\partial t}+\frac{\partial D U^{2}}{\partial x}+\frac{\partial D U V}{\partial y}=-\frac{D}{\rho} \frac{\partial P_{D}}{\partial x} \\
& -g D \frac{\partial\left(D+z_{b}\right)}{\partial x}-2 \frac{\tau_{b_{x}}}{\rho} \\
& \frac{\partial V D}{\partial t}+\frac{\partial D U V}{\partial x}+\frac{\partial D V^{2}}{\partial y}=-\frac{D}{\rho} \frac{\partial P_{D}}{\partial y} \\
& -g D \frac{\partial\left(D+z_{b}\right)}{\partial y}-2 \frac{\tau_{b_{y}}}{\rho}
\end{aligned}
$$

where $h$ :depth, $(U, V)$ :depth averaged velocity, $(M, N)$ :discharge flux vector defined as $M \equiv U h, N \equiv V h, D$ :diameter, $P_{D}$ :pressure at a top of pipe, $\left(\tau_{b_{x}}, \tau_{b_{v}}\right)$ : wall shear stress vectors.

Following the procedure of numerical simulation described in the reference 1) and 2), the flow area is divided into three parts: free surface open channel flow, pressurized pipe flow, and the interface of both flows as shown in Fig. 7. The arrangement of hydraulic variables to apply finite volume method is demonstrated in Fig. 8.

For the free surface open channel flow region, the common method ${ }^{4)}$ of flood invasion analysis in flood plains is used for the time integral of Eq. (1) (3). The over flow from box culvert is considered as free surface open channel flows, considering the unit discharge at the junction between the channel and the culvert using the weir formula, the critical flow conditions, etc.

As described in the reference 1) and 2), Eq. (4) (6) are applied to the pressurized flow region to calculate velocities and pressure. The common numerical method to calculate incompressible fluids is used for this region with the iteration procedures of pressure calculation in SMAC method ${ }^{5)}$.

The side view along the $x$-axis in Fig. 7 is shown in Fig. 9. The momentum equation at the interface is given as Eq. (7) by integrating Eq. (2) and (5) from $x_{i-1 / 2}$ to $x_{i+1 / 2}$.

$$
\begin{aligned}
& \frac{M_{i, j+1 / 2}^{n+1}-M_{i, j+1 / 2}^{n}}{\Delta t} \Delta x+(U M)_{i+1 / 2, j+1 / 2} \\
& -(U M)_{i-1 / 2, j+1 / 2}+\frac{(V M)_{i, j+1}-(V M)_{i, j}}{\Delta y} \Delta x= \\
& -g\left(\frac{h^{2}}{2}\right)_{i+1 / 2, j+1 / 2}+\left(D \frac{P_{D}}{\rho}+\frac{g D^{2}}{2}\right)_{i-1 / 2, j+1 / 2} \\
& -g D\left(z_{b_{i+1 / 2, j+1 / 2}}-z_{b_{i-1 / 2, j+1 / 2}}\right)-\left(\frac{\tau_{b_{x}}}{\rho}\right)_{i} \frac{3 \Delta x}{2}
\end{aligned}
$$


The common flood invasion analysis mentioned above is firstly applied to reproduce the flow in the steady state from the initial dry bed flume under the experimental conditions.

The constant discharge is given as the inlet boundary condition, and the discharge at the outlet is calculated using the relation between depth and discharge at the tail gate (outlet).

Since transition from free surface flow to pressurized flow occurs inside the culvert with the increase of depth, it is necessary to apply the procedures of interface tracking as follows:

The position of an interface and the depth $h$ at $t=(n-1 / 2) . \Delta t$ and $M, N$ at $t=n \Delta t$ are known. The depth $h$ at $t=(n+1 / 2) . \Delta t$ of both the free surface region and the control volume bordering an interface (Fig. 7) is calculated by Eq. (1). If $h^{n+1 / 2}$ of the free surface region is greater than $D$, the

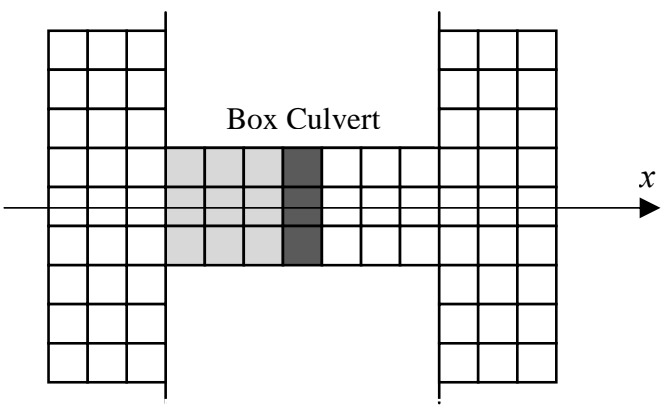

$\square$ Cell bordering interface

Pressurized flow region

Free surface flow region

Fig.7 Classification of flow domain.

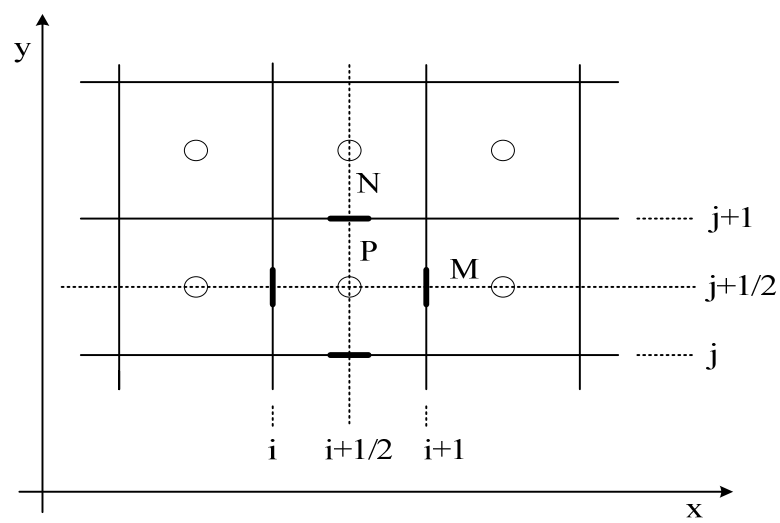

Fig.8 Arrangement of hydraulic variables.

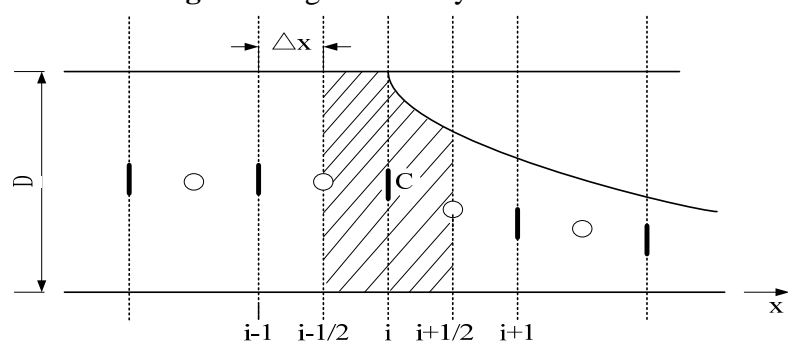

Fig.9 Side view along $x$-axis

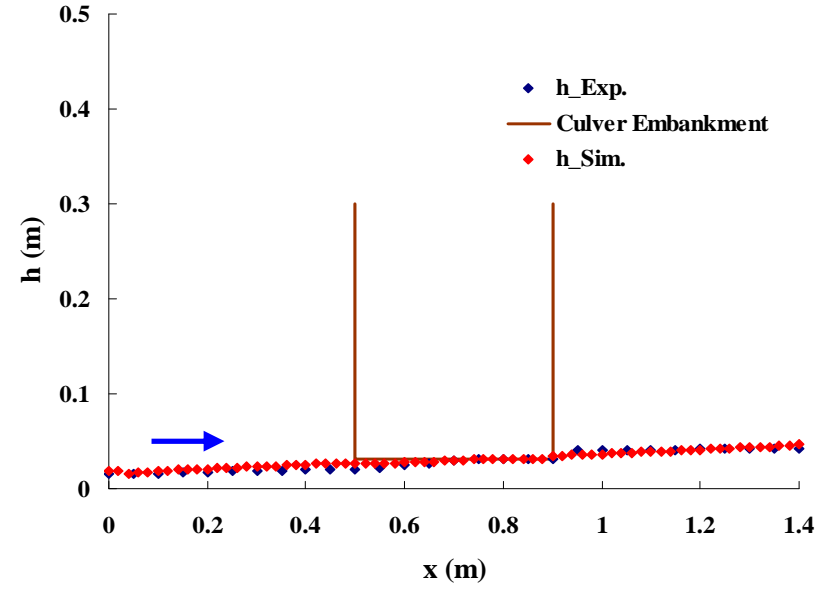

(a) Run 1

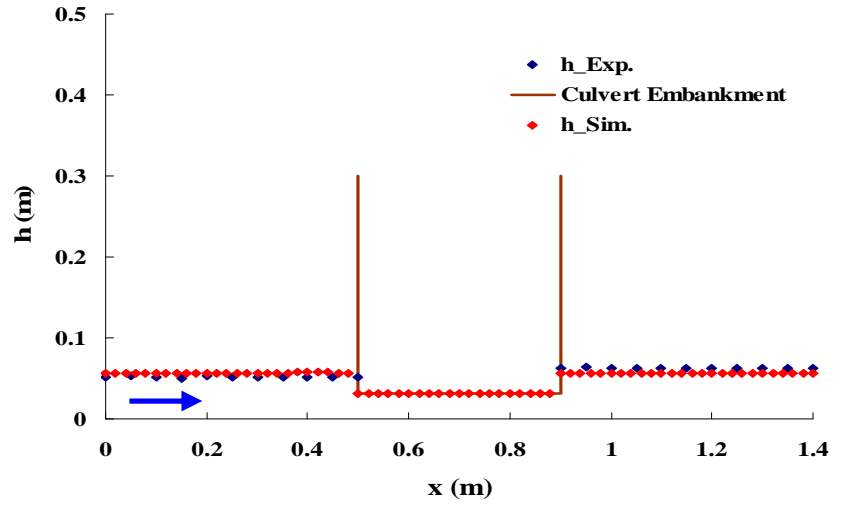

(b) Run 2

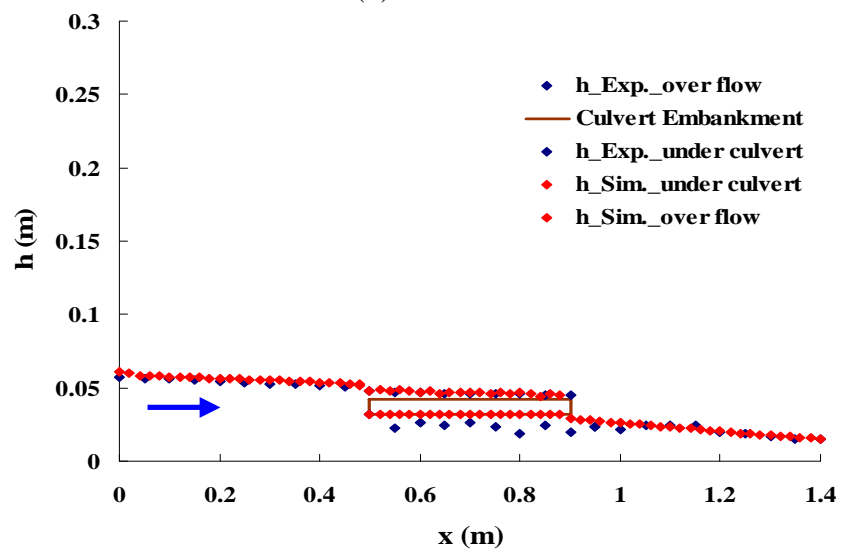

(c) Run 3

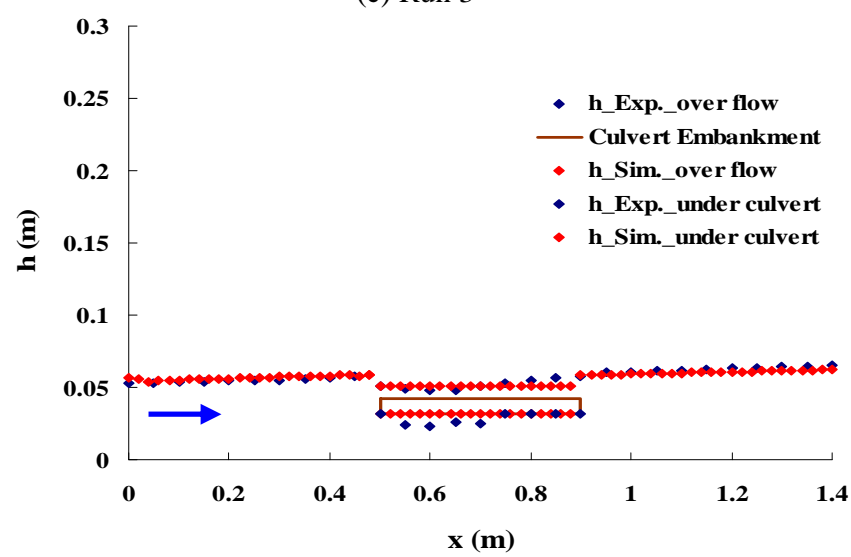

(d) Run 4

Fig.10 A verification of water depth along the centerline for both experimental and numerical results. 
control volume is regarded as the volume of the pressurized flow region. If $h^{n+1 / 2}$ of the volume bordering an interface is smaller than $D$, the volume becomes the free surface region and the new position of an interface is determined.

In case that the inlet of culvert is submerged as in Run 3 and Run 4, a model of free surface flow or pressurized flow is selected properly according to the situation of the cell at the inlet of the culvert.

\section{VERIFICATION OF RESULTS}

The fundamental two-dimensional simulation model is applied under the experimental conditions. Fig. 10 shows the water depths variations at the center line after the calculated flow results reach the steady state.

There is a good agreement between the experimental and the numerical results especially in Run 1 and Run 2 as shown in Fig. 10(a) and Fig. 10(b). In Run 3 and Run 4, where overflow and air-cavity occurred, the calculated results for the flow through culvert are not matching with observed flow, as shown in Fig. 10(c) and Fig. 10(d). These are because the model assuming hydrostatic pressure is not applicable to rapid varied flows with air cavity inside the culvert.

Using calculated results for Run 1 and Run 2, which include a partially pressurized flow part or fully pressurized flow in the culvert, respectively, we showed the temporal transition processes from free surface flow to pressurized flow in Fig. 11 and Fig. 12. Although we can't compare the calculated results with the experimental ones, the simulation model can reproduce the transition process reasonably for both cases.

\section{CONCLUSIONS}

Some of the typical features of flow through and over culverts are studied by fundamental hydraulic experiments. A two-dimensional numerical simulation model is proposed and applied under the experimental conditions, considering the interaction between open channel free surface flow and pressurized flow. As a comparison between observed and calculated results, good agreements are found between them. The model should be improved further to get better results and to be applicable to simulate flows around actual box culverts during flash flooding.

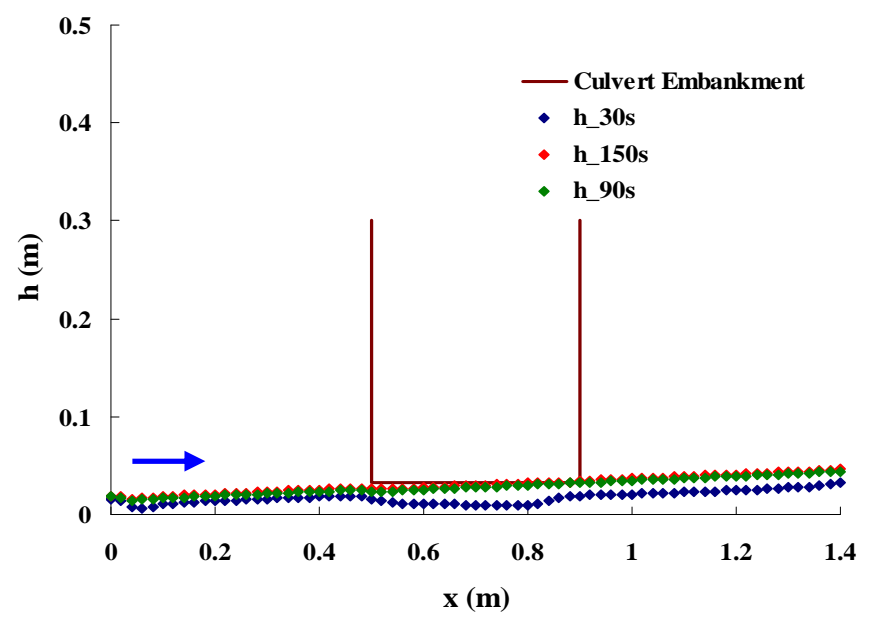

Fig.11 The interaction between free surface open channel flow and pressurized flow in Run 1.

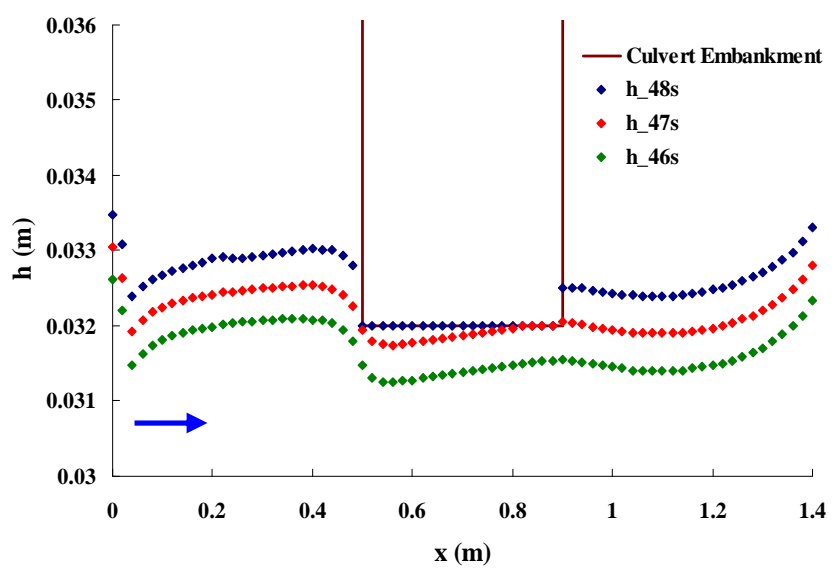

Fig.12 The hydraulic transients of the interface between free surface open channel flow and pressurized flow in Run 2.

\section{REFERENCES}

1) Hosoda, T., Inoue, K. and Tada, A.: Hydraulic transients with propagation of interface between open channel free surface flow and pressurized pipe flow, Proc. 5th International Symp. on Computational Fluid Dynamics., Sendai, Vol.I, pp.291-296, 1993.

2) Hosoda, T., Inoue, K. and Tada, A.: Hydraulic transient with propagation of interface between open channel free surface flow amd pressurized flow, Annuals, Disas. Prev. Res. Inst., Kyoto Univ., No.36, B2, pp.593-6-5, 1993 (in Japaneses).

3) Hosoda, T., Inoue, K. and Iwasa, Y.: Intrusion process of flood water into underground space, Annual J. of Hydraulic Eng., JSCE, Vol.36, pp.317-322, 1992.

4) Inoue, K.: Study on numerical method of unsteady open channel flows and its application in hydraulic engineering field, PhD thesis, Kyoto University, 1986 (in Japanese).

5) Hirt, C.W. and Cook, J.L.: Calculating three-dimensional flows around structures and over rough terrain, $J$. Computational Physics, Vol.10, pp.324-340. 1972.

(Received September 30, 2010) 